\title{
Geographic parthenogenesis in the brown alga Scytosiphon lomentaria (Scytosiphonaceae): sexuals in warm waters and parthenogens in cold waters
}

\author{
Masakazu Hoshino ${ }^{1}$, Shimpei Hiruta ${ }^{2}$, Maria Croce $^{3}$, Mitsunobu Kamiya ${ }^{4}$, Takahiro \\ Jomori $^{5}$, Toshiyuki Wakimoto ${ }^{5}$, and Kazuhiro Kogame ${ }^{6}$ \\ ${ }^{1}$ Hokkaido University Faculty of Science Graduate School of Science \\ ${ }^{2}$ National Museum of Nature and Science \\ ${ }^{3}$ Instituto Argentino de Oceanografía \\ ${ }^{4}$ Tokyo University of Marine Science and Technology \\ ${ }^{5}$ Hokkaido University Faculty of Pharmaceutical Sciences \\ ${ }^{6}$ Hokkaido University
}

March 24, 2021

\begin{abstract}
Geographic parthenogenesis (GP), a phenomenon where parthenogens and their close sexual relatives inhabit distinct geographic areas, has been considered an interesting topic to understand the adaptation to marginal habitats and the role of hybridization in evolution. Reports of GP from land and freshwater are numerous, however, this occurrence has been rarely reported on from the sea. Brown algae are mostly marine and are thought to include numerous obligate parthenogens; still, little is known about the distribution, origin, and evolution of parthenogens in this group. Here we report a novel pattern of GP in the isogamous brown alga Scytosiphon lomentaria. Sex ratio investigation demonstrated that, in Japan, sexual populations grew in the coast along warm ocean currents, whereas female-dominant parthenogenetic populations grew mainly in the coast along a cold ocean current. In the two localities where sexual and parthenogenetic populations were parapatric, parthenogens grew in more wave-exposed areas than sexuals. Population genetic and phylogenetic analyses, including those based on genome-wide single nucleotide polymorphism data, suggested that: (1) parthenogens evolved at least twice in S. lomentaria, (2) parthenogens did not originate from inter-species hybridization, (3) new parthenogenetic lineages have arisen from hybridizations between parthenogens and sexuals, and (4) parthenogens have a wider distribution than sexuals. We also showed that the production of sex pheromones, which attract male gametes, has been independently suppressed/lost in two parthenogenetic lineages. This parallel suppression/loss of the sexual trait may represent the direct origin of parthenogens, or the regressive evolution of a useless trait under asexuality.
\end{abstract}

\section{INTRODUCTION}

Although sexual reproduction is the predominant mode of reproduction in nearly all multicellular organisms, organisms reproducing only by parthenogenesis (obligate parthenogens) are numerous. An important ecological pattern is geographic parthenogenesis, a phenomenon where parthenogens and their close sexual relatives occupy distinct geographic areas. Parthenogens often have a biased distribution towards particular environmental settings (e.g., high latitude, high altitude, and deserts) when compared with close sexual relatives (Kearney, 2005). The loss of sex (or success of parthenogens) in these particular environmental settings has been an topic of interests in evolutionary biology, shedding light on the cost and benefit of sex, adaptation to marginal habitats, and the role of hybridization and polyploidy (e.g., Lynch, 1984; Bierzychudek, 1985; 
Kearney, 2005; Kawecki, 2008; Hörandl, 2009). Although reports of geographic parthenogenesis from land and freshwater are numerous, this occurrence has been rarely reported on from the sea.

Brown algae (Class Phaeophyceae, Stramenopiles) are one of few lineages to have evolved complex multicellularity (Cock et al., 2010) and most of them are exclusively marine. In brown algae, parthenogenesis, the development of a new individual from an unfertilized gamete, is a common phenomenon. Even in sexual lineages, parthenogenetic development of unfused gametes is common in laboratory cultures (Luthringer et al., 2014), and has been detected in sexual field populations at low frequency (e.g., Oppliger et al., 2007; Klochkova et al., 2017; Hoshino \& Kogame, 2019). There are numerous reports of brown algal populations which are speculated to have an obligate parthenogenetic life cycle (i.e., populations in which sexual reproduction cannot be observed; examples include Wynne, 1969; Müller, 1977; Peters, 1987; Deshmukhe \& Tatewaki, 1993; Hoshino et al., 2020a). However, there are only a few reports in which these populations were compared with their close sexual relatives and it remains largely unclear in what kind of environment parthenogenesis is favored over sexual reproduction and how parthenogens arise.

To the best of our knowledge, there are three cases in which brown algal asexuals have been compared with close sexual relatives in detail. One example is Fucus radicans, a species endemic to the brackish water of the Baltic Sea (Bergström et al., 2005). Although parthenogenesis is not known in this species, it has asexual populations that are maintained by clonal reproduction using adventitious branches (as dwarf morphotype of F. vesiculosus in Tatarenkov et al., 2005). In this species, asexual populations tend to be distributed in lower salinity areas than sexual populations (Ardehed et al., 2015). It has been posited that low salinity restricts sexual reproduction due to lysis of the egg cell or polyspermy (Serrão et al., 1999), which could favor a switch to asexual reproduction (Tatarenkov et al., 2005; Ardehed et al., 2015). Although this is a convincing and interesting hypothesis for the evolutionary process of asexual lineages, it cannot be applied to asexuals living in saline environments where the majority of brown algal asexuals occur. A second example is Mutimo cylindricus in the Japanese Islands, where female-dominant parthenogenetic populations are parapatric with sexual populations in the Tsugaru Strait (Figure 1; the strait between Hokkaido and Honshu), the northern limit of this species (as Cutleria cylindrica in Kitayama et al., 1992). However, since sex ratio investigations over the entire distributional area in Japan has not been conducted (Kitayama et al., 1992; Kogishi et al., 2010), it is unclear if the parthenogens are geographically limited to areas in the North.

The third known example is Scytosiphon lomentaria (Family Scytosiphonaceae). This algae is distributed worldwide in warm and cold temperate waters. In Japan, it has been reported from Hokkaido to Kyushu (Figure 1; Hoshino et al, 2020c). It has a heteromorphic life history, where generations of macroscopic dioicous isomorphic gametophytes alternate with generations of microscopic discoid sporophytes (Nakamura \& Tatewaki, 1975). Its sexual reproduction is isogamous; female gametes settle on the substratum sooner than male gametes and secrete sex pheromones that attract male gametes (Fu et al., 2014b). In culture condition, both female and male gametes develop parthenogenetically (Nakamura \& Tatewaki, 1975). In these Japanese populations, in addition to the sexual populations that included both female and male gametophytes, parthenogenetic populations consisting of only females are known (Hoshino et al., 2019). To date, parthenogenetic populations have been found only in Hokkaido, and sexual populations have been reported from southern Honshu (Hoshino et al., 2019). Females in the parthenogenetic populations release gametes that are larger in size, produce lesser sex pheromones, and their parthenogenetic development is rapid, compared with females in the sexual populations (Hoshino et al., 2019).

In the present study, we focused on S. lomentaria, aiming to reveal what kind of environments parthenogenesis is favored over sexual reproduction and how parthenogens have arisen. To achieve this aim, we used samples from a wide geographical range (33 localities across Japan, three localities from Europe, and two localities from Argentina), we conducted (1) sex ratio investigations, (2) phylogenetic and population genetic analyses based on mitochondrial cox 1, nuclear cetn -int2, and genome-wide single nucleotide polymorphism (SNP) markers, and (3) crossing experiments and analyses of sex pheromone production.

\section{Materials and METHODS}




\subsection{Sampling, DNA extraction, and taxonomic identity}

Scytosiphon lomentaria gametophytes examined in this study were collected from Asia (33 localities in Japan; Figure 1; population code p1-p33), Europe [two localities in Ireland (Slea Head and Portrush) and one locality in Norway (Ona)], and South America [two localities in Argentina (Puerto Madryn and San Antonio Oeste); Table 1]. These samples include specimens collected for previous studies (Kogame et al., 2005; Kogame et al., 2015a; Kogame et al., 2015b; Hoshino et al., 2019, 2020c). For newly collected samples, a fragment of each specimen was preserved in silica-gel for molecular analyses and unialgal culture isolates were also established for some samples as previously described (Kogame et al., 2015a). Pressed specimens were made for all samples and deposited as vouchers in the Herbarium of Faculty of Science, Hokkaido University, Sapporo, Japan (SAP) or in the Herbarium of Universidad Nacional der Sur, Bahia Blanca, Argentina (BBB); herbarium acronyms follow Index Herbariorum (http://sweetgum.nybg.org/science/ih/). For molecular analyses, total genomic DNA was extracted from the cultured or silica gel-dried thalli using GenCheck ${ }^{\circledR}$ DNA Extraction Reagent (FASMAC, Atsugi, Japan) following Hoshino et al. (2020b) and used as template DNA for PCR.

Since six cryptic species of $S$. lomentaria have been reported in Japan (Hoshino et al., 2020c), all samples were screened by species-check PCR. In this PCR, the partial mitochondrial cox 1 gene is amplified only in $S$. lomentaria . Primers used and PCR conditions are described in Hoshino et al. (2019). The presence/absence of PCR products was determined by $1 \%$ agarose-gel electrophoresis.

\subsection{Sex ratio investigation}

To reveal the geographical distribution of parthenogenetic (female-dominant) and sexual populations of $S$. lomentaria, sex ratios of the 38 populations (localities; Table 1) were investigated. Sex of S. lomentaria gametophytes, which is morphologically indistinguishable, was identified by sex-check PCR and/or crossing experiments. In the sex-check PCR, partial sequences of the sex-specific non-recombining region on the sex chromosome (female U chromosome and male V chromosome) of $S$. lomentaria were used as sex markers and were amplified as in Hoshino et al. (2019). The sex of each samples was confirmed by the presence/absence of PCR products in $1 \%$ agarose-gel electrophoresis. In the crossing experiments, gametes of each sample were crossed with male and female gametes from sexual populations using culture strains following the methods outlined in Hoshino et al. (2018).

\subsection{Phylogenetic analyses of mitochondrial and nuclear markers}

To roughly understand the genetic structure of parthenogenetic populations, we conducted phylogenetic analyses using the 5' end of cytochrome oxidase I ( $\operatorname{cox} 1)$ gene as a mitochondrial marker and the second intron of centrin gene (cetn -int2) which is a single copy nuclear gene in S. lomentaria (Nagasato et al., 2004). Gene amplification (PCR) and sequencing were performed as in Kogame et al. (2015a). Samples from p24 and p27contained double peaks in the PCR amplified region of their cetn -int2 gene, suggesting that these samples had multiple cetn -int2 haplotypes. Therefore, fusion cloning (Fu et al., 2014a) was performed to separate each sequence. Newly generated sequences (Table S1; cox 1: 207 sequences from 26 populations; cetn -int2: 98 sequences from 34 populations) were aligned with the previously generated sequences including those of related Scytosiphon species (Table S1; Kogame et al., 2015a; McDevit \& Saunders, 2017; Hoshino et al., 2018, 2020c) using CLustal W (Thompson et al., 1994) in MEGA v. 7 (Kumar et al., 2016) with default parameters. The cox 1 dataset was $600 \mathrm{bp}$ in length, and sequences less than $600 \mathrm{bp}$ were excluded. For the cetn -int2 dataset, gaps and highly variable regions were omitted using Gblocks web server (http://molevol.cmima.csic.es/castresana/Gblocks_server.html; Castresana, 2000) and the final dataset consisted of $604 \mathrm{bp}$.

For the cox 1 dataset, phylogenetic relationships among the haplotypes were reconstructed using medianjoining methods (Bandelt et al., 1999) in Network v. 5.0.1.0. For the cetn -int2 dataset, a maximum likelihood tree was constructed using RAxML version 8.2.10 (Stamatakis, 2014) with 1000 bootstrap pseudoreplicates under the GTR-GAMMA, through Cipres Science Gateway version 3.3 (Miller et al., 2010). 


\subsection{Population genetic analyses based on genome-wide SNPs}

\subsubsection{Library preparation and data processing}

For the discovery of single nucleotide polymorphisms (SNPs), multiplexed ISSR genotyping by sequencing (MIG-seq) was conducted following the procedure by Suyama \& Matsuki (2015) with a slight modification: annealing temperature of the first $\mathrm{PCR}$ was changed from $48^{\circ} \mathrm{C}$ to $38^{\circ} \mathrm{C}$. Both ends of fragments were obtained by paired-end sequencing (read 1 and 2), but only read 1 was used for the following analyses. Low-quality reads were removed by FASTX-Toolkit (http://hannonlab.cshl.edu/fastx_toolkit/) using quality_filteroption under the setting of $\mathrm{q}=30$ and $\mathrm{p}=40$. To remove the reads derived from extremely short library entries, the sequence primer regions in the sequences were searched and the reads which had the primer sequence were removed by FASTX-Toolkit usingfastx_clipper option.

De novo assembly was performed using Stacks v. 2.53 (Catchen et al., 2013). Since our samples were gametophytes, they were expected to be haploid. However, some samples had both female and male markers or two haplotypes of nuclear marker cetn -int2 suggesting diploidy. Therefore, at first, we performed assembly with the following parameters assuming that all samples are diploid: minimum number of identical reads required to create a stack $(\mathrm{m}=3)$, the nucleotide mismatches between loci within a single individual $(\mathrm{M}=2)$, the mismatches between loci when building the catalogue $(n=1)$, and other parameters were set default. The SNP genotype for each individual was exported using the 'populations' command; only the first SNP was extracted from each putative locus using the flags -write_single_snp. As we expected, samples having some heterozygous loci were found (all samples from p24, p27, and one samples from Ona). Then, excluding these samples, the second assembly was performed with the following parameters assuming that all samples were haploid: $\mathrm{m}=3, \mathrm{M}=0$, and $\mathrm{n}=1$. Furthermore, since calling stacks from the secondary reads (reads that are not distinguishable from sequencing error) produced heterozygosity within individuals, it was disabled using the flags -N (set to zero) and -H. Then, the SNP genotype for each individual was exported as in the diploid dataset.

Both diploid and haploid datasets were processed using PLINK v. 2.00 (Chang et al., 2015;www.coggenomics.org/plink/2.0/). SNPs with a minor allele frequency $<0.03$, loci with a missing individual rate $>0.7$, and individuals with a missing locus rate $>0.7$ were filtered out. The diploid dataset included 237 samples from 36 populations, 818 SNPs (loci), and the mean genotyping rate was $50.2 \%$. The haploid dataset included 212 samples from 34 populations, 865 SNPs (loci), and the mean genotyping rate was 48.8\%. Format of the output files of PLINK was converted using PGDSpider2 (Lischer \& Excoffier, 2012) for subsequent analyses. All samples from population p18 were removed due to their low genotyping rate.

\subsubsection{Gene diversity and clonal diversity}

Gene diversity (expected heterozygosity: $\mathrm{He}$ ) of each population was calculated using 'genetic diversity ' function of GenoDive v. 3.04 (Meirmans \& Van Tienderen, 2004; Meirmans, 2020). To examine clonal diversity, the number of clonal lineages was assessed using 'assign clone' function. The function works by first calculating a matrix of genetic distances, and then choosing a threshold distance (Meirmans, 2020). If the distance between a pair of individuals is below a threshold, they are deemed to belong to the same clonal lineage (Meirmans, 2020). We calculated a matrix of genetic distances using an infinite allele model (in this calculation, missing data were discarded) and determined the threshold distance. Each clonal lineage was treated as a single genotype and Nei's (1987) genetic diversity corrected for samples size (Div) was calculated for each population using 'clonal diversity' function. Clonal diversity index $R$ (Dorken \& Eckert, 2001) was also calculated. The index $R$ was calculated by the equation: $R=(G-1) /(N-1)$, where $G$ is the number of distinct genotypes and $N$ is the total number of sampled individuals.

\subsubsection{Population genetic structure}

To assess population genetic structure, Bayesian clustering analysis and principal component analysis (PCA) were conducted for both haploid and diploid datasets. Bayesian clustering analysis was performed using STRUCTURE v. 2.3.4 (Pritchard, Stephens, \& Donnelly, 2000). The number of clusters $(K)$ of 1-10 was 
tested by running 10 simulations for each $K$, with 100,000 Markov chain Monte Carlo steps and a burn-in of 100,000, using the model with admixture and correlated allele frequencies. The meaningful number of $K$ was determined based on the mean estimated Ln probability of the data $[\operatorname{LnP}(K)]$ and the second-order rate of change in the log probability of the data ( $\Delta K$; Evanno et al., 2005). The $\Delta K$ values were calculated using STRUCTURE HARVESTER v. 0.6.94 (Earl \& vonHoldt, 2012). Principal component analysis was performed using PLINK and the results were visualized using R software v. 3.6.0 (R Core Team, 2019). To reveal phylogenetic relationships between parthenogenetic and sexual populations, a phylogenetic network was constructed based on uncorrected $P$ distances using NeighborNet method (Bryant \& Moulton, 2004) in SplitsTree v. 4.15.1 (Huson \& Bryant, 2006).

\subsection{Sex pheromone production}

Molecular data suggested that the Pacific coast parthenogenetic populations are genetically distinct from the Sea of Japan coast parthenogenetic populations which include 22 of which sex pheromone production was analyzed in Hoshino et al., (2019). Thus, the parthenogens in the Pacific coast were newly examined whether they produce sexual pheromone using a gas chromatography/mass spectrometry (GCMS). Females from parthenogenetic population p28 were used for GCMS. Cultured gametophytes were kept in $300 \mathrm{~mL}$ of sterilized seawater in a $500 \mathrm{~mL}$ flask at $15^{\circ} \mathrm{C}$ and gametes were released in the flask. Volatile secretions were trapped on Mono Trap RCC18 (GL science, Tokyo, Japan) using a closed-loop-stripping system at $15^{\circ} \mathrm{C}$. After looping for $15 \mathrm{~h}$, absorbed volatile compounds were eluted with $50 \mu \mathrm{L}$ of $\mathrm{CH}_{2} \mathrm{Cl}_{2}$ and immediately analyzed by GCMS. [Zebron ZB-wax (phenomenex) $30 \mathrm{~m} \times 0.25 \mu \mathrm{m}$; He as the carrier gas; program rate: $45-$ $200^{\circ} \mathrm{C}$ at $5^{\circ} \mathrm{C} / \mathrm{min}$. Compounds were identified by using the NIST MS library and similarity search program. A female gametophyte from sexual population p15 was also examined as positive control.

\section{RESULTS}

\subsection{Sex ratio and geographic distribution of sexual and parthenogenetic populations}

Results of sex check by sex-check PCR and crossing experiments were concordant, except for some samples from p24, p27, and Argentina which had both female and male markers in sex-check PCR (Figure 1; Table 1; Table S1). In crossing experiments, samples from p27 released gametes fused with male gametes of p22 (Table S1) and did not function as male gametes. Therefore, the samples having both markers were considered female (at least, phenotypically).

Populations were considered sexual when at least one male was identified, or parthenogenic when no males could be identified in samples of ten or more individuals (Table 1). For p1, although the sex of only two individuals were examined, this population was considered parthenogenetic (Table 1), since sexual reproduction was not observed in this population in a previous study (Kogame et al., 2005). Along the Sea of Japan coast, sexual populations were distributed from Kyushu to Hokkaido and overlapped with parthenogenetic populations on the west coast of Hokkaido (Figure 1). Along the Pacific coast, sexual populations were limited to the South of Choshi, Chiba Prefecture (the sampling locality of p24 and p25) and parthenogenetic populations were found North of Choshi (Figure 1). Sexual and parthenogenetic populations were parapatric in two localities: Esashi, the west coast of Hokkaido (p4 and p5) and Choshi (p24 and p25). At these localities, the two types of populations were $1 \mathrm{~km}$ and $0.3 \mathrm{~km}$ apart along the coast, respectively (Figure S1). In both localities, parthenogenetic populations were found in more upper part of intertidal zone and more wave-exposed areas, compared with sexual populations. No males were found among European and Argentinean samples (four and 17 samples, respectively; Table S1).

\section{$3.2 \operatorname{cox} 1$ haplotype network}

A total of 37 haplotypes were detected in S. lomentaria, and these haplotypes formed three haplogroups (group A-C; Figure 2). Group A had 26 haplotypes and was detected throughout Japan, Europe, North America (both Pacific and Atlantic coasts), and Argentina. Group B had six haplotypes and was detected in the Sea of Japan coast of southern Honshu and North America. Group C had five haplotypes and was detected from the Pacific coast of central Honshu. Samples of parthenogenetic populations in Japan had 
group A haplotypes without exception. Most haplotypes from Europe, North America, and Argentina were identical or close to those from parthenogenetic populations from Japan and formed a big star-like network pattern (i.e., one frequent haplotype together with several less frequent haplotypes). Group A included haplotypes which did not found in male samples (haplotypes indicated by arrowheads in Figure 2).

\section{3 cetn-int2 molecular phylogeny}

Populations from the Pacific coast and the Sea of Japan coast tended to have different haplotypes, but this tendency was not clear in the populations from Kyushu and Tsugaru Strait (p16, p30, and p31) where the two seas meet (Figures 1 and 3). Samples from parthenogenetic populations p24 and p27 had two cetn -int2 haplotypes; the one haplotype was common in the Pacific coast parthenogenetic populations and the other was common in the Sea of Japan coast sexual populations (Figure 3).

\subsection{SNPs data analyses}

\subsubsection{Genetic diversity and clonal diversity}

Parthenogenetic populations often showed lower gene diversity ( He ; Table 1); gene diversity was around 0.10 in most sexual populations, while that of parthenogenetic populations was often below 0.05 . The high gene diversity of parthenogenetic populations p24 and p27 is probably because individuals in these populations have two distinct genomes.

Genetic distances between individuals showed that parthenogenetic populations included more genetically identical/nearly identical individuals than sexual populations (Figure 4). Histograms of the genetic distances based on haploid and diploid datasets were similar in shape, except for that the genetic distances based on the diploid dataset (Figure S2) doubled those of the haploid dataset (Figure 4). Histograms based on haploid dataset showed that pairs of individuals having genetic distance of less than 11 were rare in sexual populations (i.e., seven pairs), but abundant in parthenogenetic populations (i.e., 221 pairs; Figure 4). A previous study showed that parthenogenesis rarely occurred in a sexual population of Scytosiphon shibazakiorum (as Scytosiphon species IIa; Hoshino \& Kogame, 2019), a close relative of S. lomentaria. Therefore, we considered that the genetic distances observed in sexual populations (larger than 11) are the genetic distances mostly between sexually produced individuals (i.e., gametophytes generated through meiosis in sexually produced sporophytes), and the genetic distances between individuals belonging to the same clonal lineage are smaller than those. Thus, a threshold distance distinguishing whether pairs of individuals belonging to the same clonal lineage was set to 10 (shown in Figure 4 as broken lines). For the diploid dataset, a threshold distance was set to 20 . In the haploid dataset, 27 clones were assumed from 93 parthenogenetic population individuals, 114 clones were assumed from 119 sexual population individuals, and 138 clones were assumed in total (three clonal lineages c5, c28, and c53 were shared by both parthenogenetic and sexual populations; Table 1). In the diploid dataset, 33 clones were assumed from 118 parthenogenetic population individuals, 115 clones were assumed from 119 sexual population individuals, and 145 clones were assumed in total (three clonal lineages were shared by both parthenogenetic and sexual populations).

Most sexual populations had genetic diversity (Div) and clonal diversity index $(R)$ of nearly 1.0, while those of parthenogenetic populations were usually below 0.5 (Table 1). Each parthenogenetic population usually had unique clonal lineages, but several clonal lineages were shared by multiple populations. For example, lineage c5 was found in three parthenogenetic populations (p28, p29, and p32) and also in a sexual population $\mathrm{p} 6$, and lineage $\mathrm{c} 28$ was found in a sexual population $\mathrm{p} 25$ and also in a parthenogenetic population p26 (Table 1). Argentinean populations had clonal lineages (c44 and c98) which were found from Japanese parthenogenetic populations $\mathrm{p} 2$ and $\mathrm{p} 29$.

\subsubsection{Population genetic structure}

Three different analyses revealed that Japanese populations of $S$. lomentaria fall into two genetically differentiated groups, the Pacific coast populations and the Sea of Japan coast populations, regardless of the reproductive mode of the populations (Figures 5-7). Populations around Kyushu and the Tsugaru Strait were intermediates connecting the two groups of populations. Samples from Argentina and Europe were 
genetically close to those from parthenogenetic populations in Japan. Furthermore, judging from the results, sexual population p6 and p25 seemed to include parthenogenetic lineages (clonal lineages c5 and c28 in Table $1)$, in addition to sexual lineages.

In the STRUCTURE analysis based on the diploid dataset, the $\log$-likelihood of the data, $\operatorname{LnP}(K)$, increased with increasing $K$ until $K=7$ and the ideal number of clusters determined by the Evanno method (Evanno et al., 2005) was $K=2$ (the $\Delta K$ value showed a single peak at $K=2$; Figure S3). At $K=2$, in all runs, clear genetic differentiation was observed between the Pacific coast populations and the Sea of Japan coast populations (although p33 was from the Pacific coast, it was clustered with the Sea of Japan coast populations; Figure 5). An admixture between the two genetic clusters was observed in the populations from Kyushu and the Tsugaru Strait, suggesting the occurrence of gene flow between the two groups. Although sex-check PCR, cetn -int2 data, and SNPs data suggested that p24 and p27 had two distinct genomes, an admixture of two clusters was not estimated in them, except for two runs at $K=3$. In the two runs at $K=$ 3 , the cluster of the Sea of Japan coast populations in $K=2$ were divided into the west coast of Hokkaido populations (p1-p6) and the Honshu populations (p7-p16), and an admixture between the west coast of Hokkaido populations and the Pacific coast populations were observed in p24 and p27 and also in p30 and p31. In other runs at $K=3, \mathrm{p} 24$ and p27 formed a cluster with the sexual or parthenogenetic populations from the Pacific coast. In the runs at $K>3, \mathrm{p} 24$ and p27 formed an independent cluster with or without p30. In the NJ trees constructed by STRUCTURE, the cluster was genetically intermediate between clusters of Pacific coast populations and those of Sea of Japan coast populations (e.g., Figure 5b, c). At $K=5$, in five of 10 runs, the Sea of Japan populations were divided into two clusters (west coast of Hokkaido populations and the Honshu populations) and the Pacific coast populations were divided into three clusters (a cluster of sexual populations and two clusters of parthenogenetic populations; Figure 5).

In the PCA (Figure 6), PC1 roughly divided the Japanese populations into two groups: Pacific coast, and Sea of Japan coast, and explained $26.6 \%$ of the variance. The PC2 captured north-south variation along it in each group and explained $15.9 \%$ of the variance. The PCA appeared as if the individuals were plotted in a ring along the coast of the Japanese Islands; individuals from Kyushu (p16 and p17) and near the Tsugaru Strait (p5, p6, p30, p31) connected the edges of the two groups (Figure 6a). Each group was roughly divided into sexual and parthenogenetic populations along PC3 which explained $11.5 \%$ of the variance (Figure $6 \mathrm{~b}$ ). Samples from parthenogenetic populations p24 and p27, which were likely to be polyploid, were close to those from parthenogenetic populations around the Tsugaru Strait (p30-p32). In parthenogenetic populations (p1, $\mathrm{p} 2$, p4, p24, and p26-p33), the plots tended to be more densely clustered, relative to the sexual populations. This is probably due to the lower genetic variance of each parthenogenetic population.

The NeighborNet network showed polyphyly of parthenogenetic populations (Figure 7). The network also supported the genetic differentiation between the Pacific coast group and the Sea of Japan coast group. Populations around Kyushu (p15-p17) and the Tsugaru Strait (p5, p6, p30, p31) were intermediates connecting the two groups.

For the three analyses described above, no significant differences were observed between diploid and haploid datasets (Figures S4-S6).

\subsubsection{Sex pheromone production}

Analyses using GCMS did not detect sex pheromones from the female gametes of parthenogenetic population p28 (Figure. 8). The compounds predicted as brown algal sex pheromones were detected only from the positive control (female gametes from sexual populations p15) with high intensity at around 12.1 and 14.6 min (Figure. 8). In the similarity search for the first compound, the first candidate was 6-[(1Z )-1-butenyl]1,4-cycloheptadiene [ectocarpene (Maier \& Müller, 1986); similarity value $=97 \%$ ] and the second candidate was 6-[(1E )-1-butenyl]-1,4-cycloheptadiene (thecis-trans isomer of ectocarpene; similarity value $=93 \%$ ). For the second compound, the first candidate was ectocarpene (similarity value $=95 \%$ ) and the second candidate was $(3 E, 5 E, 8 E)$-1,3,5,8-undecatetraene (similarity value $=91 \%$ ).

\section{DISCUSSION}


This study shed light on biogeographic and evolutionary questions involving the parthenogens of brown algae by focusing on a species that is widely distributed - a topic that has been rarely studied within this group of organisms. Firstly, we found a novel pattern of geographic parthenogenesis in the brown alga $S$. lomentaria. Across various sampling sites in Japan, sexuals were found in localities influenced by warm ocean currents, whereas parthenogens were mainly found in localities influenced by a cold ocean current. When parthenogens and sexuals were parapatric, parthenogens were biased to wave-exposed areas. This type of distributional pattern of parthenogens had probably not been described until now so far, at least for brown algae. Secondly, we demonstrated that parthenogens have evolved at least twice in S. lomentaria. Although the origin of these parthenogens was unclear, our data indicated that they did not originate from interspecies hybridization, as is common in animals and land plants. Thirdly, we found that new parthenogenetic lineages arose through hybridization between the parthenogens and their parental sexuals. Finally, we also showed that the sexual trait (sex pheromone production) has been independently lost/suppressed in the two parthenogenetic lineages.

\subsection{Geographic parthenogenesis in S. lomentaria}

We showed that, along the coast of Sea of Japan, sexuals were distributed from Kyushu to the west coast of Hokkaido and overlapped with parthenogens along the west coast of Hokkaido. In contrast, along the Pacific coast, sexuals were distributed south of Choshi (the sampling locality of p24 and p25) and parthenogens were distributed north of Choshi. Choshi, close to where the Kuroshio current and Oyashio current meet, is known as one of the boundaries of seaweed flora in the Pacific coast; it is the southern limit of cold waters species (Okamura, 1931; Yoshizaki, 1979). The northern limit of subtropical species, the Cape Taito $\left(35^{\circ} 18^{\prime} \mathrm{N}, 140^{\circ} 24^{\prime} \mathrm{E}\right)$, is also near Choshi (Okamura, 1931; Yoshizaki, 1979). On the other hand, the seaweed flora along the coast of the Sea of Japan is generally warm temperate being affected by the Tsushima Current, a relatively smaller warm current that bifurcates from the Kuroshio Current. Furthermore, the Tsugaru Strait has been suggested as a boundary of seaweed floras (Okamura, 1931; Yoshizaki \& Tanaka, 1986). Considering the above, the distribution of sexuals and parthenogens of Japanese S. lomentaria seems to be heavily associated with ocean currents.

In Esashi (p4 and p5) and Choshi (p24 and p25), where sexual and parthenogens are parapatric, parthenogens grew in the upper more wave-exposed intertidal zones compared with sexuals. Intertidal seaweed species often grow in specific vertical or horizontal "zones" or "bands" that respond to environmental gradients caused by wave exposure and abiotic conditions resulting from tidal levels (e.g., temperature, salinity, dehydration, light intensity), partly due to interspecific differences in the tolerance to the environmental stress (Hurd et al., 2014). The above habitat segregation between parthenogenetic and sexual populations provides evidence for niche differentiation. Our SNP-based analyses suggested that the two sexual populations near Esashi and Choshi (p6 and p25) included parthenogenetic lineages that have probably never hybridized with sexuals, however, it is unknown if sexuals and parthenogens had habitat segregation, also in these localities.

In Japan, It has been often suggested that parthenogenetic organisms tend to be biased towards marginal and disturbed environments, when compared with their close sexual relatives (Tilquin \& Kokko, 2016). Lynch (1984) hypothesize that the association of parthenogens with marginal habitats may be a consequence of selection pressure over parthenogens to use habitat that is not occupied by the parental sexuals. Lynch (1984) mentioned "since one of the most stringent requirements for the establishment and maintenance of a parthenogen will be the avoidance of backcrosses and competition with parental sexuals, incipient clones that tend to use habitats not normally occupied by the parental sexuals will have an initial selective advantage over other clone." In S. lomentaria , parthenogens and sexuals clearly occupied different ecological niches. However, it is unclear whether the cold waters and the wave-exposed areas, where parthenogens existed, are the marginal/disturbed habitats for sexuals. Although we have performed culture experiments at $10^{\circ} \mathrm{C}$, $15^{\circ} \mathrm{C}$, and $20^{\circ} \mathrm{C}$, at least for the gametophytic phase, no difference was observed in the growth and maturity between the culture isolates from parthenogenetic and sexual populations (data not shown). Further study is necessary to examine whether sporophytes of sexuals can mature (i.e., whether sexuals complete their life cycle) in low temperature. Wave-exposed areas, on the other hand, are possibly unsuitable habitats for 
sexuals since waves can disturb interaction between male and female gametes. In some oogamous brown algae, laboratory experiments have shown that gamete release is enhanced in calm/no-flow conditions and is inhibited in shaken/high-flow conditions (Gordon \& Brawley, 2004; Pearson \& Serrão, 2006). However, it is unclear if $S$. lomentaria sexual populations are distributed in wave-exposed areas in warm regions where parthenogenetic populations are not distributed.

\subsection{Do parthenogens have larger distributions than sexuals?}

Parthenogens often occupy larger distribution areas than their sexual relatives (Bierzychudek, 1985; Hörandl, 2009). This could be also the case of $S$. lomentaria. We found that populations from Argentina and Europe included no males and they were genetically close/identical to parthenogenetic populations in Japan. Regarding populations in North America, although only cox 1 data was available, most of them had haplotypes which were close/identical to those from the parthenogenetic populations in Japan. Furthermore, sexual reproduction (gamete fusions) has not been reported from S. lomentaria in North America (Wynne, 1969). These facts suggest that the populations of $S$. lomentariafrom Argentina, Europe, and North America are parthenogenetic and that parthenogens of this species are more widely distributed than sexuals.

To explain a larger distribution of parthenogens, two hypotheses focusing on a selection among genetically diverse parthenogenetic clones (clonal selection) are often cited: "general-purpose genotype" (GPG) and "frozen niche-variation" (FNV) hypotheses. The GPG hypothesis supposes that clonal selection promotes the evolution of highly generalized (or general-purpose) genotypes, which are characterized by both broad tolerance ranges and low fitness variance for relevant environmental gradients; it expects that a widespread distribution of a parthenogen has resulted from the dispersal of a single (several) highly generalized clone(s) (Lynch, 1984). The FNV hypothesis, on the other hand, expects that a widespread distribution of a parthenogen has resulted from the joint distribution of many locally adapted (specialist) clones (Vrijenhoek, 1984; Hörandl, 2009). In S. lomentaria, several parthenogenetic clones (or clonal lineages) were found in multiple populations and had wide distributions, as the GPG hypothesis expects. However, the whole parthenogenetic populations consisted of about 30 polyphyletic clones and the major clone in each parthenogenetic population was often unique to the population. Although it is unknown if each clone is locally adapted or not, this high clonal diversity seems to fit the FNV hypothesis.

Another important factor to explain a wide distribution of parthenogens is a superior colonization ability. Parthenogens should have a significant advantage over bi-sexual parents in colonization, since they can initiate a new colony by a single individual and their potential increase in numbers per generation is double that of a bi-sexual parent (Cuellar, 1977). Parthenogens are known to be commonly biased towards previously glaciated areas, and it has been speculated that it is partly because of that parthenogens have occupied these areas after the glaciation as a consequence of their superior colonization ability (Kearney, 2005). The last glacial maximum impacted on the distribution of seaweeds and some seaweeds show shallow population structure probably due to postglacial northward recolonization from southern glacial refugia (e.g., Provan et al., 2005; Hoarau et al., 2007; Coyer et al., 2011; Neiva et al., 2014). Judging from our cox 1-haplotype network, the population structure of Japanese parthenogenetic populations was not so shallow, but populations from North America, which are probably parthenogenetic, showed a clear star-like network pattern. It may suggest the recent population expansion (i.e., postglacial recolonization) of $S$. lomentaria parthenogens in North America. The superior colonization ability of parthenogens should also be advantageous in expanding the distribution as invasive species. In the brown algae Cutleria multifida and Mutimo cylindrica, populations that seems to have been introduced are usually female-dominant (probably parthenogenetic populations; Kogishi et al., 2010; Kawai et al., 2016). Our SNPs-based analyses showed that most Argentinean samples were genetically identical to those from the Japanese parthenogenetic population $\mathrm{p} 2$. These Argentinean parthenogenetic populations may have been introduced from Japan, as has been hypothesized for other seaweed that are considered to be introduced from Asia to Argentina (Hoshino et. al., 2020a).

\subsection{The origin of parthenogens}

Molecular analyses demonstrated that parthenogens have evolved at least twice in S. lomentaria . Parthe- 
nogens from the Sea of Japan coast and those from the Pacific coast probably have independent origins. Parthenogens from the Sea of Japan coast (p1, p2, and p4) likely have evolved from the sexuals of the west coast of Hokkaido (p3, p5, and p6) which are the closest sexual relatives. Although p33 is in the Pacific coast, it was genetically close to parthenogens from the Sea of Japan. It may suggest that parthenogens from the Sea of Japan coast have spread to the Pacific coast along ocean currents (Figure. 1). Parthenogens from the Pacific coast (p26, p28, p29, and p32) were genetically the closest to the sexuals of the Pacific coast (p19-p22 and p25), suggesting that the parthenogens have evolved around the northern limit of sexuals in the Pacific coast. In the NeighborNet, parthenogens of p24 and p27 and those around the Tsugaru Strait (p30-p32) appeared to be distinct lineages from those of the Sea of Japan (p1, p2, and p4) and the Pacific coast (p26, p28, p29, and p32). However, judging from the results of STRUCTURE analyses and PCA, they probably originated from hybridization between sexuals from the Sea of Japan coast and existing parthenogens from the Pacific coast (i.e., contagious origin; Simon et al., 2003). Polyploidy of parthenogens of p24 and p27 may indicate that meiosis was disturbed for some reason after the hybridization. Although a backcross with their parental sexuals has been considered a taboo for the maintenance of parthenogens (Lynch, 1984), it might have occurred multiple times in S. lomentaria and provided genetic diversity in parthenogens. Parthenogens of organisms having a haploid generation likeS. lomentaria are expected to be more susceptible to the accumulation of deleterious mutations compared with parthenogens having diploid or higher ploidy. In S. lomentaria parthenogens, backcrosses with sexual relatives may have the benefits of eliminating accumulated mutations and acquiring a new genome. However, considering that there are sexual populations that probably originated from hybridization between parthenogens and sexuals (p4, p5, p25; Figure 5), some parthenogens may have been assimilated into sexuals through hybridization. It may suggest that parthenogens also have a risk of extinction through hybridization with their parental sexuals, as Lynch (1984) pointed out.

Although the origins of parthenogens are not always known, inter-specific hybridization and polyploidy are considered as major triggers for parthenogenesis in animals and land plants (Simon et al., 2003; Kearney, 2005; Hörandl, 2009). But it is probably not the case for S. lomentaria. The parthenogenetic populations did not show evidence for inter-specific hybridization, such as mitochondrial introgression. Some parthenogenetic individuals seemed to be polyploid; however,cetn -int2 analysis showed that these polyploid samples from p24 and p27 originated from intra-specific crossing, not inter-specific hybridization as we mentioned above.

The most plausible explanation for the origin of $S$. lomentariaparthenogens might be the spontaneous origin, that is, spontaneous loss of sexuality or acquisition of asexuality through mutation (Simon et al., 2003). In S. lomentaria, parthenogenesis of unfused gametes is common in culture condition, even in individuals from sexual populations (Hoshino et al., 2019). Thus, we expect that if sexual reproduction is somehow disturbed (e.g., due to environmental factors or loss of sexual traits), parthenogenetic ability will be under strong selection and individuals with high parthenogenetic ability, that is high enough to maintain obligate parthenogenetic life cycle, will be easily selected. Although S. lomentaria is isogamous and both female and male gametes have parthenogenetic ability, male parthenogens were not found. This is probably due to the more inferior parthenogenetic ability of male gametes than that of females (Hoshino et al., 2019; Hoshino \& Kogame, 2019). Females are likely to have more potential than males to evolve into parthenogens in this species.

We have shown parallel suppression/loss of sex pheromone production in parthenogens from the Sea of Japan coast and from the Pacific coast (Hoshino et al., 2019; this study). Sex pheromone production can be considered an essential trait for effective sexual reproduction, and the spontaneous loss of such traits can trigger the evolution of parthenogens. So, suppression/loss of sex pheromone production can be considered the direct origin of the parthenogens. Another possible explanation is that sex pheromone production was suppressed after the evolution of parthenogens due to regressive evolution. In asexual life cycles, sex pheromone production is useless and can be considered a neutral or maladaptive trait depending on the amount of energy cost required for their expression as we pointed out previously (Hoshino et al., 2019). It has been suggested that a formerly adaptive trait can be reduced, when that trait is neutral or maladaptive in the new selective environment (Lynch, 1984; Lahti et al., 2009; van der Kooi \& Schwander, 2014). In animal 
parthenogens, the decay of female sexual traits has been widely reported (van der Kooi \& Schwander, 2014). At present, it is unclear whether the suppression/loss of sex pheromone production inS. lomentaria occurred before or after the evolution of parthenogens.

\section{Acknowledgments}

We thank Dr. Tsuyoshi Abe, Mr. Takashi Abe, Mr. Koji Shibazaki, Ms. Kumiko Shibazaki for their help in sampling. We also thank Dr. Wilfred Santiañez, Dr. Davis Iritani, and Dr. Kevin Wakeman for the critical reading of this manuscript. MH was supported by MIKIMOTO FUND FOR MARINE ECOLOGY and JSPS KAKENHI (grant number JP19J10967). KK was supported by JSPS KAKENHI (grant number JP19K06817).

\section{Data availability}

Newly generated sequences ( $\operatorname{cox} 1$ and cetn -int2) were deposited in DNA Data Bank of Japan (accession number: LC619340- LC619644; Table S1). SNPs datasets were uploaded to Dryad: DOI https://doi.org/10.5061/dryad.8pk0p2nmx.

\section{Author's contributions}

MH, MEC, MK and KK collected the materials in this study. MH and AFH conducted MIG-seq. MH and KK conducted culture experiments. TJ and TW conducted GCMS analyses of sex pheromones. MH conducted phylogenetic and population genetic analyses. $\mathrm{MH}$ and $\mathrm{KK}$ wrote the manuscript with input from all authors.

Table 1 . Sample information and genetic diversity of each populations. Sex ratio, the number of female: the number of male: the number of samples having both famal and male markers in sex check PCR. reproductive mode of each population is indicated as $\mathrm{S}$ (sexual population) and $\mathrm{P}$ (parthenogenetic population). $N$, the number of samples from which SNPs data was successfully obtained; $G$, the number of distinct genotypes (distinct clonal lineages); He, gene diversity; Div, genetic diversity corrected for samples size; $R$, clonal diversity index. Clone codes are given to each clonal lineage; the clonal lineages found in multiple populations are indicated in bold and those from diploid samples are in underlined. For clonal lineages which found in multiple individuals in one population, the number of individuals is shown in parentheses. Values of genetic diversity indices are based on calculations using the haploid dataset, except for p24 and p27.

\begin{tabular}{|c|c|c|c|c|c|c|}
\hline Population code & Locality & GPS & Sex ratio $(::)$ & Sexual mode & $N$ & $G$ \\
\hline $\mathrm{p} 1$ & Asari, Hokkaido & $43^{\circ} 10^{\prime} 35.5^{\prime \prime} \mathrm{N} 141^{\circ} 04^{\prime} 00.1^{\prime \prime} \mathrm{E}$ & $2: 0: 0$ & $\mathrm{P}$ & 2 & 1 \\
\hline $\mathrm{p} 2$ & Oshoro, Hokkaido & $43^{\circ} 12^{\prime} 54.0^{\prime \prime} \mathrm{N} 140^{\circ} 51^{\prime} 12.3 " \mathrm{E}$ & $35: 0: 0$ & $\mathrm{P}$ & 8 & 5 \\
\hline p3 & Shimamaki, Hokkaido & $42^{\circ} 42^{\prime} 46.2^{\prime \prime} \mathrm{N} 140^{\circ} 03^{\prime} 50.6^{\prime \prime} \mathrm{E}$ & $4: 1: 0$ & $\mathrm{~S}$ & 5 & 2 \\
\hline $\mathrm{p} 4$ & Eshashi, Hokkaido & $41^{\circ} 52^{\prime} 06.3^{\prime \prime} \mathrm{N} 140^{\circ} 06^{\prime} 43.6^{\prime \prime} \mathrm{E}$ & 21:0:0 & $\mathrm{P}$ & 8 & 1 \\
\hline p5 & Eshashi, Hokkaido & $41^{\circ} 51^{\prime} 58.3^{\prime \prime} \mathrm{N} 140^{\circ} 06^{\prime} 49.0^{\prime \prime} \mathrm{E}$ & $4: 2: 0$ & $\mathrm{~S}$ & 6 & 6 \\
\hline p6 & Shirakami, Hokkaido & $41^{\circ} 23^{\prime} 52.1^{\prime \prime} \mathrm{N} 140^{\circ} 11^{\prime} 56.0^{\prime \prime} \mathrm{E}$ & $5: 1: 0$ & $\mathrm{~S}$ & 6 & 6 \\
\hline p7 & Fukaura, Aomori Pref. & $40^{\circ} 46^{\prime} 08.6^{\prime \prime} \mathrm{N} 140^{\circ} 03^{\prime} 09.9^{\prime \prime} \mathrm{E}$ & $3: 3: 0$ & $\mathrm{~S}$ & 6 & 6 \\
\hline $\mathrm{p} 8$ & Akita-shirakami, Akita Pref. & $40^{\circ} 23^{\prime} 05.7^{\prime \prime} \mathrm{N} 139^{\circ} 59^{\prime} 05.6^{\prime \prime} \mathrm{E}$ & $0: 1: 0$ & $\mathrm{~S}$ & 1 & 1 \\
\hline p9 & Kosagawa, Akita Pref. & $39^{\circ} 08^{\prime} 04.0 " \mathrm{~N} 139^{\circ} 53^{\prime} 02.9^{\prime \prime} \mathrm{E}$ & $9: 4: 0$ & $\mathrm{~S}$ & 8 & 8 \\
\hline p10 & Nagatejima, Ishikawa Pref. & $36^{\circ} 57^{\prime} 03.7^{\prime \prime} \mathrm{N} 136^{\circ} 45^{\prime} 23.2^{\prime \prime} \mathrm{E}$ & $4: 6: 0$ & $\mathrm{~S}$ & 8 & 8 \\
\hline p11 & Mihama, Fukui Pref. & $35^{\circ} 36^{\prime} 43.2^{\prime \prime} \mathrm{N} 135^{\circ} 53^{\prime} 30.8^{\prime \prime} \mathrm{E}$ & $6: 5: 0$ & $\mathrm{~S}$ & 8 & 7 \\
\hline p12 & Shikimi, Fukui Pref. & $35^{\circ} 33^{\prime} 46.6^{\prime \prime} \mathrm{N} 135^{\circ} 50^{\prime} 11.3 " \mathrm{E}$ & $15: 13: 0$ & $\mathrm{~S}$ & 8 & 8 \\
\hline p13 & Miyatsu, Kyoto Pref. & $35^{\circ} 32^{\prime} \mathrm{N} 135^{\circ} 11^{\prime} \mathrm{E}$ & 1:1:0 & $\mathrm{S}$ & 2 & 2 \\
\hline p14 & Yurihama, Tottori Pref. & $35^{\circ} 30^{\prime} \mathrm{N} 133^{\circ} 54^{\prime} \mathrm{E}$ & $2: 4: 0$ & $\mathrm{~S}$ & 7 & 7 \\
\hline p15 & Kiwado, Yamaguchi Pref. & $34^{\circ} 23^{\prime} 12.4^{\prime \prime} \mathrm{N} 131^{\circ} 08^{\prime} 31.2^{\prime \prime} \mathrm{E}$ & $1: 1: 0$ & $\mathrm{~S}$ & 1 & 1 \\
\hline p16 & Koinoura, Fukuoka Pref. & $33^{\circ} 47^{\prime} 49.6^{\prime \prime} \mathrm{N} 130^{\circ} 26^{\prime} 54.7^{\prime \prime} \mathrm{E}$ & $3: 8: 0$ & $\mathrm{~S}$ & 8 & 8 \\
\hline p17 & Sakurajima, Kagoshima Pref. & $31^{\circ} 34^{\prime} 49.0^{\prime \prime} \mathrm{N} 130^{\circ} 35^{\prime} 36.1^{\prime \prime} \mathrm{E}$ & $2: 3: 0$ & $\mathrm{~S}$ & 2 & 1 \\
\hline p18 & Murozumi, & $33^{\circ} 55^{\prime} \mathrm{N} 131^{\circ} 58 \mathrm{E}$ & $2: 1: 0$ & $\mathrm{~S}$ & 0 & NA \\
\hline p19 & Hazumisaki, Nagoya Pref. & $34^{\circ} 41^{\prime} 51.4^{\prime \prime} \mathrm{N} 136^{\circ} 58^{\prime} 11.6^{\prime \prime} \mathrm{E}$ & $9: 12: 0$ & $\mathrm{~S}$ & 8 & 8 \\
\hline
\end{tabular}




\begin{tabular}{|c|c|c|c|c|c|c|}
\hline Population code & Locality & GPS & Sex ratio $(::)$ & Sexual mode & $N$ & $G$ \\
\hline p20 & Shimoda, Shizuoka Pref. & $34^{\circ} 39^{\prime} 58.4^{\prime \prime} \mathrm{N} 138^{\circ} 56^{\prime} 09.2^{\prime \prime} \mathrm{E}$ & $12: 6: 0$ & $\mathrm{~S}$ & 8 & 8 \\
\hline p21 & Enoshima, Kanagawa Pref. & $35^{\circ} 17^{\prime} 52.4^{\prime \prime} \mathrm{N} 139^{\circ} 28^{\prime} 46.2^{\prime \prime} \mathrm{E}$ & $15: 9: 0$ & $\mathrm{~S}$ & 8 & 8 \\
\hline p22 & Kannonzaki, Kanagawa Pref. & $35^{\circ} 15^{\prime} 22.9^{\prime \prime} \mathrm{N} 139^{\circ} 44^{\prime} 45.7^{\prime \prime} \mathrm{E}$ & $2: 3: 0$ & $\mathrm{~S}$ & 4 & 4 \\
\hline p23 & Katsuura, Chiba Pref. & $35^{\circ} 08^{\prime} 01.8^{\prime \prime} \mathrm{N} 140^{\circ} 17^{\prime} 02.4^{\prime \prime} \mathrm{E}$ & $3: 7: 0$ & $\mathrm{~S}$ & 0 & NA \\
\hline p24 & Choshi, Chiba Pref. & $35^{\circ} 42^{\prime} 19.5^{\prime \prime} \mathrm{N} 140^{\circ} 51^{\prime} 52.6^{\prime \prime} \mathrm{E}$ & $12: 0: 4$ & $\mathrm{P}$ & 16 & 1 \\
\hline p25 & Choshi, Chiba Pref. & $35^{\circ} 42^{\prime} 22.8^{\prime \prime} \mathrm{N} 140^{\circ} 52^{\prime} 02.7^{\prime \prime} \mathrm{E}$ & $8: 6: 0$ & $\mathrm{~S}$ & 15 & 15 \\
\hline $\mathrm{p} 26$ & Shioyazaki, Fukushima Pref. & $36^{\circ} 59^{\prime} 50.8^{\prime \prime} \mathrm{N} 140^{\circ} 58^{\prime} 53.6^{\prime \prime} \mathrm{E}$ & $22: 0: 0$ & $\mathrm{P}$ & 8 & 2 \\
\hline $\mathrm{p} 27$ & Azukihama, Miyagi Pref. & $38^{\circ} 17^{\prime} 41.9 ” \mathrm{~N} 141^{\circ} 04^{\prime} 29.8^{\prime \prime} \mathrm{E}$ & $7: 0: 26$ & $\mathrm{P}$ & 8 & 2 \\
\hline $\mathrm{p} 28$ & Miyako, Iwate Pref. & $39^{\circ} 39^{\prime} 01.6 ” \mathrm{~N} 141^{\circ} 58^{\prime} 48.7^{\prime \prime} \mathrm{E}$ & 14:0:0 & $\mathrm{P}$ & 8 & 2 \\
\hline p29 & Kabushima, Aomori Pref. & $40^{\circ} 32^{\prime} 19.4^{\prime \prime} \mathrm{N} 141^{\circ} 33^{\prime} 30.9^{\prime \prime} \mathrm{E}$ & 28:0:0 & $\mathrm{P}$ & 8 & 2 \\
\hline p30 & Nanae, Hokkaido & $41^{\circ} 48^{\prime} 42.8^{\prime \prime} \mathrm{N} 140^{\circ} 42^{\prime} 12.2^{\prime \prime} \mathrm{E}$ & 39:0:0 & $\mathrm{P}$ & 7 & 2 \\
\hline p31 & Cape Tachimachi, Hokkaido & $41^{\circ} 44^{\prime} 40.6^{\prime \prime} \mathrm{N} 140^{\circ} 43^{\prime} 18.1^{\prime \prime} \mathrm{E}$ & 28:0:0 & $\mathrm{P}$ & 8 & 7 \\
\hline p32 & Muroran, Hokkaido & $42^{\circ} 18^{\prime} 20.9 ” \mathrm{~N} 140^{\circ} 59^{\prime} 01.0 " \mathrm{E}$ & 38:0:0 & $\mathrm{P}$ & 10 & 3 \\
\hline p33 & Aikappu, Hokkaido & $43^{\circ} 00^{\prime} 54.4^{\prime \prime} \mathrm{N} 144^{\circ} 49^{\prime} 58.8^{\prime \prime} \mathrm{E}$ & 21:0:0 & $\mathrm{P}$ & 8 & 2 \\
\hline $\mathrm{PM}$ & Puerto Madryn, Argentina & $42^{\circ} 46^{\prime} 47^{\prime \prime} \mathrm{S}, 65^{\circ} 00^{\prime} 05^{\prime \prime} \mathrm{W}$ & $6: 0: 3$ & $\mathrm{P} ?$ & 7 & 3 \\
\hline $\mathrm{SAO}$ & San Antonio Oeste, Argentina & $40^{\circ} 43^{\prime} 15^{\prime \prime} \mathrm{S}, 64^{\circ} 56^{\prime} 29^{\prime \prime} \mathrm{W}$ & $6: 0: 2$ & $\mathrm{P} ?$ & 8 & 1 \\
\hline $\mathrm{SH}$ & Slea Head, Ireland & $52^{\circ} 06^{\prime} 33^{\prime \prime} \mathrm{N}, 10^{\circ} 27^{\prime} 54^{\prime \prime} \mathrm{W}$ & $1: 0: 0$ & $?$ & 1 & 1 \\
\hline PORT & Portrush, Ireland & $55^{\circ} 12^{\prime} 37^{\prime \prime} \mathrm{N}, 6^{\circ} 39^{\prime} 18^{\prime \prime} \mathrm{W}$ & $1: 0: 0$ & $?$ & 1 & 1 \\
\hline ONA & Ona, Norway & $62^{\circ} 51^{\prime} 46^{\prime \prime} \mathrm{N}, 6^{\circ} 32^{\prime} 50^{\prime \prime} \mathrm{E}$ & $2: 0: 0$ & $?$ & 2 & 2 \\
\hline
\end{tabular}

Figure 1. Map showing the population localities and the sex ratio of each population. A population code (p1-p33) is given to each population. Pie-charts show sex ratio investigated by sex check PCR or crossing experiments: females are represented in black, males are represented in white, and samples from which both female and male markers amplified in the sex check PCR are represented in grey. Pie-chart sizes are proportional to the corresponding sample size. TS, Tsugaru Strait; KC, Kuroshio warm ocean current; TC, Tsushima warm ocean current; OC, Oyashio cold ocean current; ESC, East Sakhalin cold ocean current.

Figure 2 . Cox 1-haplotype network. Population codes [1-33 (without 'p')] are given to the haplotypes of Japanese samples. Sampling regions are represented as different colors. For the samples from Japan, samples from sexual and parthenogenetic populations were represented in different colors. Each colored circle represents a haplotype and its size is proportional to its frequency, whereas white circles represent hypothetical unsampled haplotypes. White squares represent median vectors. Haplotypes indicated by arrowheads were found in 6-45 samples of which sex was identified, but none of these samples were identified as male (female or samples having both female and male markers).

Figure 3 . Maximum likelihood (ML) tree based on the nuclearcetn -int2 (604 bp). Numbers on branches indicate bootstrap percentage from ML analysis. Only bootstrap percentages [?] $60 \%$ are shown. The labels of samples Japanese from parthenogenetic populations are indicated in red color, those from Japanese sexual populations are in black, and those from Argentina and Europe are in blue. Asterisks are given to the samples from the Sea of Japan coast (p1-p16), and stars are given to the samples from the Tsugaru Strait and Kyushu (p6, p16, p17, p30, and p31). Arrowheads indicate the two haplotypes found in samples from p24 and p27.

Figure 4. Histograms showing genetic distances between samples based on the haploid dataset. (a) Genetic distances in parthenogenetic populations. (b) Genetic distances in sexual populations. The threshold distances (10) to recognize clonal lineages is indicated by broken lines. Samples from Europe and Argentina are included in the histogram for parthenogenetic populations. Note that, in the actual calculation in 'assign clone' function of GenoDive, the dataset was not separated into sexual and parthenogenetic populations.

Figure 5. Result of the STRUCTURE analyses based on the diploid dataset when $K=2$ and $K=5$. The frequency of each cluster in each sample is shown by the bar plot. Sampling region in the Japanese Islands 
are shown above the bar plot, and population codes [1-33 (without 'p'), ARG: Argentina, EUR: Europe; parthenogenetic populations from Japan are indicated in red] are shown below the bar plot. (a) The genetic clusters estimated in all runs at $K=2$; (b) The genetic clusters estimated in five of 10 runs at $K=5$; (c) The Neighbor Joining tree for the five clusters at $K=5$ shown in (b). Color for each cluster is consistent in the bar plot of (b) and the NJ tree.

Figure 6 . Result of the PCA based on the diploid dataset showing the locations of each individual on the first three principal components (PC1-PC3), which describe $54 \%$ of the genetic variation. (a) Plot for the first and second PC. (b) Plot for the first and third PC. In Sampling localities of each Japanese population are shown in the map of Japan shown above the charts. Colors for each population are consistent in the PCA plots and the map.

Figure 7 . The NeighborNet tree based on the diploid dataset, showing the polyphyly of parthenogenetic populations. Labels of population codes of parthenogenetic populations from Japan are indicated in red. Japanese population are roughly color-coded according to the regions: the Pacific coast (deep blue), around the Tsugaru Strait (orange), around Kyushu (green), and the Sea of Japan coast (rose).

Figure 8 . Results of the GCMS analyses of the volatile compounds released from gametes: extracted ion chromatograms $=148-149 \mathrm{~m} / z$. The compounds predicted as sex pheromones were detected with high intensity at around 12.1 and $14.6 \mathrm{~min}$ from female gametes of a sexual population (p15; asterisks), not from those of parthenogenetic population p28. For the first compound, the fisrt candidate was ectocarpene and the second candidate was the cis-trans isomor of ectocarpene. For the second compound, the first candidate was ectocarpene and the second candidate was ( $3 E, 5 E, 8 E$ )-1,3,5,8-undecatetraene.

\section{References}

Ardehed, A., Johansson, D., Schagerström, E., Kautsky, L., Johannesson, K. \& Pereyra, R. T. (2015). Complex spatial clonal structure in the macroalga Fucus radicanswith both sexual and asexual recruitment. Ecology and Evolution ,5 (19), 4233-4245. doi:10.1002/ece3.1629

Bandelt, H.-J., Forster, P. \& Röhl, A. (1999). Median-joining networks for inferring intraspecific phylogenies. Molecular Biology and Evolution , 16 (1), 37-48. doi: 10.1093/oxfordjournals.molbev.a026036

Bergström, L., Tatarenkov, A., Johannesson, K., Jönsson, R. B. \& Kautsky, L. (2005). Genetic and morphological identification ofFucus radicans sp. nov. (Fucales, Phaeophyceae) in the brackish Baltic Sea. Journal of Phycology , 41 (5), 1025-1038. doi: 10.1111/j.1529-8817.2005.00125.x

Bierzychudek, P. (1985). Patterns in plant parthenogenesis.Experientia , 41 , 1255-1264. doi: 10.1007/9783-0348-6273-8_9

Bryant, D. \& Moulton, V. (2004). Neighbor-Net: an agglomerative method for the construction of phylogenetic network. Molecular Biology and Evolution , 21 (2), 255-265. doi: 10.1093/molbev/msh018

Castresana, J. (2000). Selection of conserved blocks from multiple alignments for their use in phylogenetic analysis. Molecular Biology and Evolution , 17 (4), 540-552. doi:10.1093/oxfordjournals.molbev.a026334

Catchen, J., Hohenlohe, P. A., Bassham, S., Amores, A. \& Cresko, W. A. (2013). Stacks: an analysis tool set for population genomics.Molecular Ecology ,22 (11), 3124-3140. doi: 10.1111/mec.12354

Chang, C. C., Chow, C. C., Tellier, LCAM., Vattikuti, S., Purcell, S M. \& Lee, J. J. (2015). Second-generation PLINK: rising to the challenge of larger and richer datasets. GigaScience , 4 (1), 7. doi: 10.1186/s13742015-0047-8

Cock, J. M., Sterck, L., Rouzé, P., Scirnet, D., Allen, A. E., Amoutzias, G., ... Wincker, P. (2010). The Ectocarpus genome and the independent evolution of multicellularity in brown algae.Nature , 465, 617-621. doi: $10.1038 /$ nature09016 
Coyer, J. A, Hoarau, G., Costa, J. F., Hogerdijk, B., Serrão, E, A., Billard, E., .. Olsen, J. L. (2011). Evolution and diversification within the intertidal brown macroalgae Fucus spiralis /F. vesiculosus species complex in the North Atlantic. Molecular Phylogenetic and Evolution , 58 (2), 283-296. doi: 10.1016/j.ympev.2010.11.015

Cuellar, O. (1977). Animal parthenogenesis. Science ,197 (4306), 837-843. doi: 0.1126/science.887925

Deshmukhe, G. V. \& Tatewaki, M. (1993). Occurrence of somatic diploidization in the life history of Coilodesme japonica(Dictyosiphonales, Phaeophyta). Phycologia , 32 (3), 197-203. doi. 10.2216/i0031-8884-32-3197.1

Dorken, M. E. \& Eckert, C. G. (2001). Severely reduced sexual reproduction in northern populations of a clonal plant, Decodon verticillatus (Lythraceae). Journal of Ecology , 89 (3), 339-250. doi: 10.1046/j.13652745.2001.00558.x

Earl, D. A. \& vonHoldt, B. M. (2012). STRUCTURE HARVESTER: a website and program for visualizing STRUCTURE output and implementing the Evanno method. Conservation Genetics Resources , 4 , 359-361. doi: $10.1007 / \mathrm{s} 12686-011-9548-7$

Evanno, G., Regnaut, S. \& Goudet, J. (2005). Detecting the number of clusters of individuals using the software STRUCTURE: a simulation study. Molecular Ecology , 14 (8), 2611-2620. doi: 10.1111/j.1365294X.2005.02553.x

Fu, C., Donovan, W. P., Shikapwashya-Hasser, O., Ye, X. \& Cole, R. H. (2014a). Hot fusion: an efficient method to clone multiple DNA fragments as well as inverted repeats without ligase. PLoS One ,9 (12), e115318. doi: 10.1371/journal.pone.0115318

Fu, G., Kinoshita, N., Nagasato, C. \& Motomura, T. (2014b). Fertilization of brown algae: flagellar function in phototaxis and chemotaxis. In: Sawada, H., Inoue, N. \& Iwano, M. (Eds.), Sexual reproduction in animals and plants . (pp. 339-367). Tokyo: Springer.

Gordon, R. \& Brawley, S. H. (2004). Effects of water motion on propagule release from algae with complex life histories. Marine Biology , 145 , 21-29. doi:10.1007/s00227-004-1305-y

Hoarau, G., Coyer, J. A., Veldsink, J. H., Stam, W. T. \& Olsen, J. L. (2007). Glacial refugia and recolonization pathways in the brown seaweed Fucus serratus . Molecular Ecology , 16 (17), 3606-3616. doi: 10.1111/j.1365294X.2007.03408.x

Hoshino, M., Ishikawa, S. \& Kogame, K. (2018). Concordance between DNA-based specie boundaries and reproductive isolating barriers in theScytosiphon lomentaria species complex (Ectocarpales, Phaeophyceae). Phycologia , 57 (2), 232-242. doi: 10.2216/17-77.1

Hoshino, M. \& Kogame, K. (2019). Parthenogenesis is rare in the reproduction of a sexual field population of the isogamous brown algaScytosiphon (Scytosiphonaceae, Ectocarpales). Journal of Phycology , 55 (2), 466-472. doi: 10.1111/jpy.12835.

Hoshino, M., Okino, T. \& Kogame, K. (2019). Parthenogenetic female populations in the brown alga Scytosiphon lomentaria(Scytosiphonaceae, Ectocarpales): Decay of a sexual trait and acquisition of asexual traits. Journal of Phycology ,55 (1), 204-213. doi: 10.1111/jpy.12812

Hoshino, M., Croce, M. E., Hanyuda, T. \& Kogame, K. (2020a). Species delimitation of Planosiphon gracilis morphospecies (Scytosiphonaceae, Phaeophyceae) from Japan and the description of Pl. nakamurae sp. nov. Phycologia , 59 (2), 116-126. doi: 10.1080/00318884.2019.1709144

Hoshino, M., Ino, C., Kitayama, T. \& Kogame, K. (2020b). Integrative systematics approaches revealed that the rare red algaSchimmelmannia (Shimmelmanniaceae, Acrosymphytales) from Japan is a new species: the description of $S$. benzaiteniana sp. nov.Phycological Research , 68 (4), 290-297. doi: 10.1111/jpy.13089 
Hoshino, M., Tanaka, A., Kamiya, M., Uwai, S., Hiraoka, M. \& Kogame, K. (2020c). Systematics, distribution, and sexual compatibility of sexScytosiphon species (Scytosiphonaceae, Ectocarpales) from Japan and the description of four new species. Journal of Phycologyin press . doi:10.1111/jpy.13089

Hurd, C. L., Harrison, P. J., Bischof, K. \& Lobban, C. S. (2014).Seaweed ecology and physiology (2nd ed.). Cambridge: Cambridge University Press.

Huson, D. H. \& Bryant, D. (2006). Application of phylogenetic networks in evolutionary studies. Molecular Biology and Evolution ,23 (2), 254-267. doi: 10.1093/molbev/msj030

Hörandl, E. (2009). Geographical parthenogenesis: opportunities for asexuality. In Schön, I., Martens, K. \& van Dijk, P (Eds.), Lost sex. (pp.161-186). Dordrecht: Springer.

Kawai, H., Kogishi, K., Hanyuda, T., Arai, S., Gurgel, F. C., Nelson, W., .. Peters, A. F. (2016). Phylogeographic analysis of the brown alga Cutleria multifida (Tilopteridales, Phaeophyceae) suggests a complicated introduction history. Phycological Research ,64 (1), 3-10. doi: 10.1111/pre.12113

Kawecki, T. J. (2008). Adaptation to marginal habitats. Annual Review of Ecology Evolution and Systematics , 39 , 321-342. doi: 10.1146/annurev.ecolsys.38.091206.095622

Kearney, M. (2005). Hybridization, glaciation and geographical parthenogenesis. Trends in Ecology EJ Evolution , 20(9), 495-502. doi: 10.1016/j.tree.2005.06.005

Kitayama, T., Kawai, H. \& Yoshida, T. (1992). Dominance of female gametophytes in field populations of Cutleria cylindrica(Cutleriales, Phaeophyceae) in the Tsugaru Strait, Japan.Phycologia , 31 (5), 449-461. doi: 10.2216/i0031-8884-31-5-449.1

Klochkova, T. A., Klochkova, N. G., Yotsukura, N. \& Kim, G. H. (2017). Morphological, molecular, and chromosomal identification of dwarf haploid parthenosporophytes of Tauya basicrassa (Phaeophyceae, Laminariales) from the Sea of Okhotsk. Algae, 32 (1), 15-28. doi: 10.4490/algae.2017.32.1.31

Kogame, K., Uwai, S., Shimada, S. \& Masuda, M. (2005). A study of sexual and asexual populations of Scytosiphon lomentaria(Scytosiphonaceae, Phaeophyceae) in Hokkaido, northern Japan, using molecular markers. European Journal of Phycology , 40 (3), 313-322. doi: 10.1080/09670260500193008

Kogame, K., Ishikawa, S., Yamauchi, K., Uwai, S., Kurihara, A. \& Masuda, M. (2015a). Delimitation of cryptic species of theScytosiphon lomentaria complex (Scytosiphonaceae, Phaeophyceae) in Japan, based on mitochondrial and nuclear molecular markers.Phycological Research , 63 (3), 167-177. doi: 10.1111/pre.12091

Kogame, K., Rindi, F., Peters, A. F. \& Guiry, M. D. (2015b). Genetic diversity and mitochondrial introgression in Scytosiphon lomentaria (Ectocarpales, Phaeophyceae) in the north-eastern Atlantic Ocean. Phycologia , 54 (4), 367-374. doi: 10.2216/15-016.1

Kogishi, K., Kitayama, T., Miller, K. A., Hanyuda, T. \& Kawai, H. (2010). Phylogeography of Cutleria cylindrica (Cutleriales, Phaeophyceae) in northeastern Asia, and the identity of an introduced population in California. Journal of Phycology , 46 (3), 553-558. doi: 10.1111/j.1529-8817.2010.00818.x

Kumar, S., Stecher, G. \& Tamura, K. (2016). MEGA7: Molecular Evolutionary Genetics Analysis version 7.0 for bigger datasets. Molecular Biology and Evolution 33(7), 1870-1874. doi: 10.1093/molbev/msw054

Lahti, D. C., Johnson, N. A., Ajie, B. C., Otto, S. P., Hendry, A. P., Blumstein, D. T., ... Foster S. A. (2009). Relaxed selection in the wild. Trends in Ecology and Evolution, 24 (9), 487-496. doi: 10.1016/j.tree.2009.03.010

Lischer, H. E.L. \& Excoffier, L. (2012). PGDSpider: An automated data conversion tool for connecting population genetics and genomics programs. Bioinformatics , 28 (2), 298-299. doi: 10.1093/bioinformatics/btr642

Luthringer, R., Cormier, A., Ahmed, S., Peters, A. F., Cock, J. M. \& Coelho, S. M. (2014). Sexual dimorphism in the brown algae.Perspectives in Phycology , 1 (1), 11-25. doi: 10.1127/2198-011X/2014/0002 
Lynch, M. (1984). Destabilizing hybridization, general-purpose genotypes and geographic parthenogenesis. The Quarterly Review of Biology ,59 (3), 257-290. doi: 10.1086/413902

Maier, I. \& Müller, D. G. (1986). Sexual pheromones in algae. The Biological Bulletin , 170 , 145-175.

McDevit, D. C. \& Saunders, G. W. (2017). A molecular investigation of Canadian Scytosiphonaceae (Phaeophyceae) including descriptions of Planosiphon gen. nov. and Scytosiphon promiscuus sp. nov.Botany, 95 (7), 653-671. doi: 10.1139/cjb-2017-0042

Meirmans, P. G. \& Van Tienderen, P. H. (2004). GENOTYPE and GENODIVE: two programs for analysis of genetic diversity of asexual organisms. Molecular Ecology , 4 (4): 792-794. doi: 10.1111/j.14718286.2004.00770.x

Meirmans, P. G. (2020). GenoDive version 3.0: easy-to-use software for the analysis of genetic data of diploids and polyploids. Molecular Ecology Resources , 20 (4), 1126-1131. doi: 10.1111/1755-0998.13145

Miller, M. A., Pfeiffer, W. \& Schwartz, T. (2010/ November 14). Creating the CIPRES Science Gateway for inference of large phylogenetic trees . Paper presented at the Proceedings of the Gateway Computing Environments Workshop (GCE). doi: 10.1109/GCE.2010.5676129

Müller, D. G. (1977). Sexual reproduction in British Ectocarpus siliculosus (Phaeophyta).British Phycological Journal , 12 (2), 131-136. doi: 10.1080/00071617700650141

Nagasato, C., Uemori, C., Kato, A. \& Motomura, T. (2004). Characterization of centrin genes from Ochromonas danica(Chrysophyceae) and Scytosiphon lomentaria (Phaeophyceae).Phycological Research, 52 (3), 266-272. doi: 10.1111/j.1440-183.2004.00347.x

Nakamura, Y. \& Tatewaki, M. (1975). The life history of some species of Scytosiphonales. Scientific Papers of the Institute of Algological Research Faculty of Science Hokkaido University , 6 (2), 57-93.

Nei, M. (1987). Molecular Evolutionary Genetics. New York: Colombia University Press.

Neiva, J., Assis, J., Fernandes, F., Pearson, G. A. \& Serrão, E. A. (2014). Species distribution models and mitochondrial DNA phylogeography suggest an extensive biogeographical shift in the high-intertidal seaweed Pelvetia canaliculata . Journal of Biogeography , 41 (6), 1137-1148. doi: 10.1111/jbi.12278

Okamura, K. (1931). Kaisansyokubutsu no chiritekibunpu . Tokyo: Iwanami Shoten.

Oppliger, L. V., Correa, J. A. \& Peters, A. F. (2007). Parthenogenesis in the brown alga Lessonia nigrescens (Laminariales, Phaeophyceae) from central Chile. Journal of Phycology ,43 (6), 1295-1301. doi: 10.1111/j.1529-8817.2007.00408.x

Pearson, G. A. \& Serrão, E. A. (2006). Revisiting synchronous gamete release by fucoid algae in the intertidal zone: fertilization success and beyond? Integrative and Comparative Biology , 46 (5), 587-597. doi: 10.1093/icb/icl030

Peters, A. F. (1987). Reproduction and sexuality in the Chordariales (Phaeophyceae). A review of culture studies. In Round, F. E. \& Chapman, D. J. (Eds.), Progress in Phycological Research. Vol. 5 (pp. 223-263). Bistol: Biopress Ltd.

Pritchard, J. K., Stephens, M. \& Donnelly, P. (2000). Inference of population structure using multilocus genotype data. Genetics ,155 (2), 945-959.

Provan, J., Wattier, R. A. \& Maggs, C. A. (2005). Phylogeographic analysis of the red seaweed Palmaria palmata reveals a Pleistocene marine glacial refugium in the English Channel.Molecular Ecology , 14 (3), 793-803. doi: 10.1111/j.1365-294X.2005.02447.x

R Core Team. (2019). R: A language and environment for statistical computing. Vienna,, Austria: R Foundation for Statistical Computing. 
Serrão, E. A., Brawley, S. H., Hedman, J., Kautsky, L. \& Samuelsson, G. (1999). Reproductive success of Fucus vesiculosus (Phaeophyceae) in the Baltic Sea. Journal of Phycology , 35 (2), 254-269. doi: 10.1046/j.15298817.1999.3520254.x

Simon, J.-C., Delmotte, F., Rispe, C. \& Crease, T. (2003). Phylogenetic relationships between parthenogens and their sexual relatives: the possible routes to parthenogenesis in animals. Biological Journal of the Linnean Society , 79 (1): 151-163. doi: 10.1046/j.1095-8312.2003.00175.x

Stamatakis, A. (2014). RAxML version 8: a tool for phylogenetic analysis and post-analysis of large phylogenies. Bioinformatics ,30 (9): 1312-1313. doi: 10.1093/bioinformatics/btu033

Suyama, Y. \& Matsuki, Y. (2015). MIG-seq: an effective PCR-based method for genome-wide singlenucleotide polymorphism genotyping using the next-generation sequencing platform. Scientific Report , 5 , 16963. doi: 10.1038/srep16963

Tatarenkov, A., Bergström, L., Jönsson, R. B., Serrão, E. A., Kautsky, L. \& Johannsson, K. (2005). Intriguing asexual life in marginal populations of the brown seaweed Fucus vesiculosus .Molecular Ecology , 14 (2), 647-651. doi: 10.1111/j.1365-294X.2005.02425.x

Thompson, J. D., Higgins, D. G. \& Gibson, T. J. (1994). CLUSTAL W: improving the sensitivity of progressive multiple sequence alignment through sequence weighting, position-specific gap penalties and weight matrix choice. Nucleic Acids Research , 22 (22): 4673-4680. doi: 10.1093/nar/22.22.4673

Tilquin, A. \& Kokko, H. (2016). What does the geography of parthenogenesis teach us about sex? Philosophical Transactions of the Royal Society B , 371 (1706), 20120538. doi: 10.1098/rstb.2015.0538

Vrijenhoek, R. C. (1984). Ecological differentiation among clones: the frozen niche variation model. In Wöhrmann, K. \& Loeschcke, V. (Eds.)Population Biology and Evolution. (pp. 218-231). Berlin, Heidelberg: Springer.

Wynne, M. J. (1969). Life history and systematic studies of some Pacific North American Phaeophyceae (brown algae). University of California Publications in Botany , 50 , 1-88.

Yoshizaki, M. (1979). Geographic distribution of marine algae of the Pacific coast of Japan, with special reference to algal flora of the Kii Peninsula. Memoirs of the National Science Museum , 12 , 201-211.

Yoshizaki, M. \& Tanaka, J. (1986). Biogeography of marine algae on the Japan Sea coast of Japan, with special reference to algal flora of the Noto peninsula. Memoirs of the National Science Museum ,19 , 109-119.

van der Kooi, C. \& Schwander, T. (2014). On the fate of sexual traits under asexuality. Biological Reviews , 89 (4), 805-819. doi: 10.1111/brv.12078 


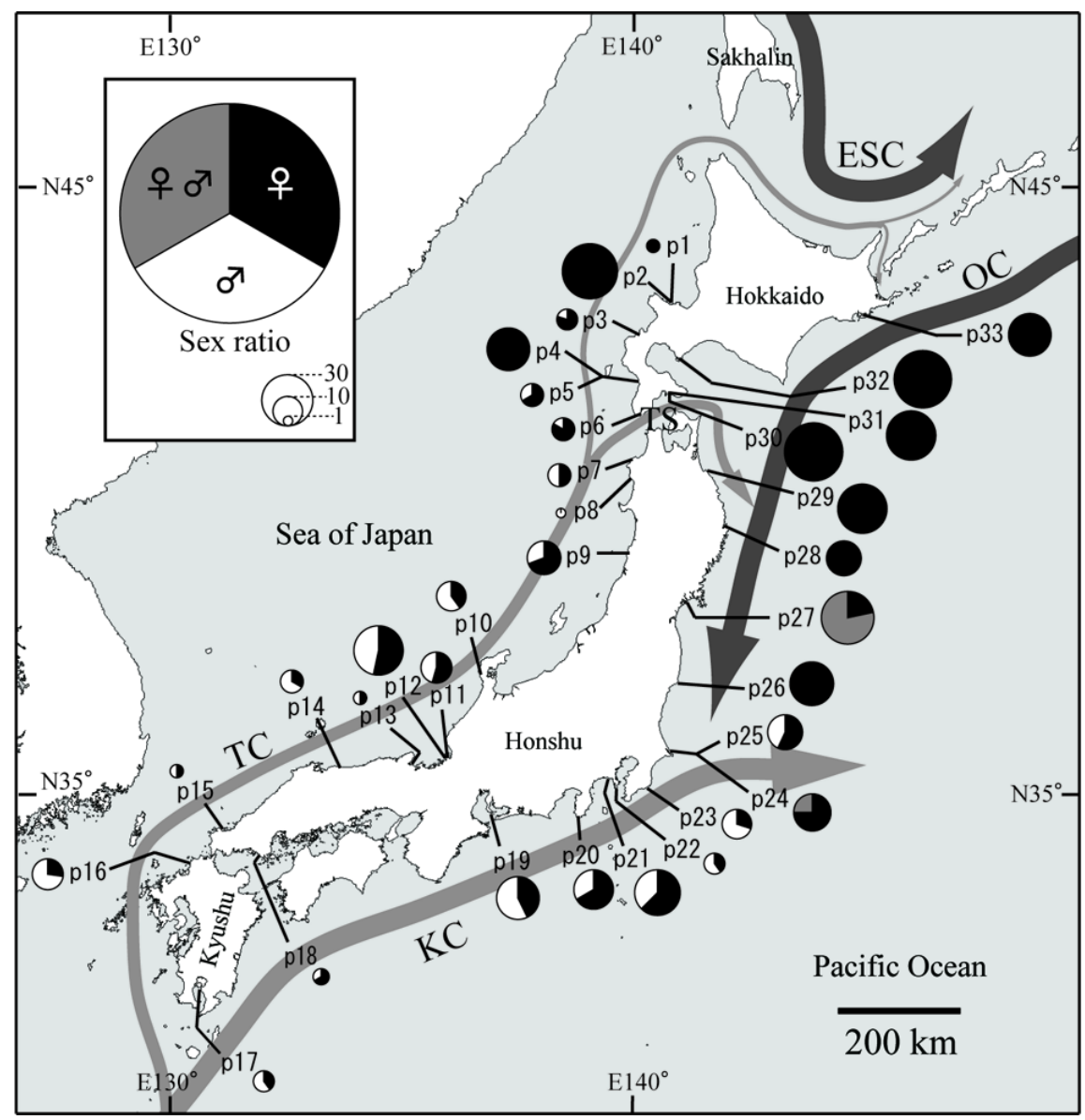




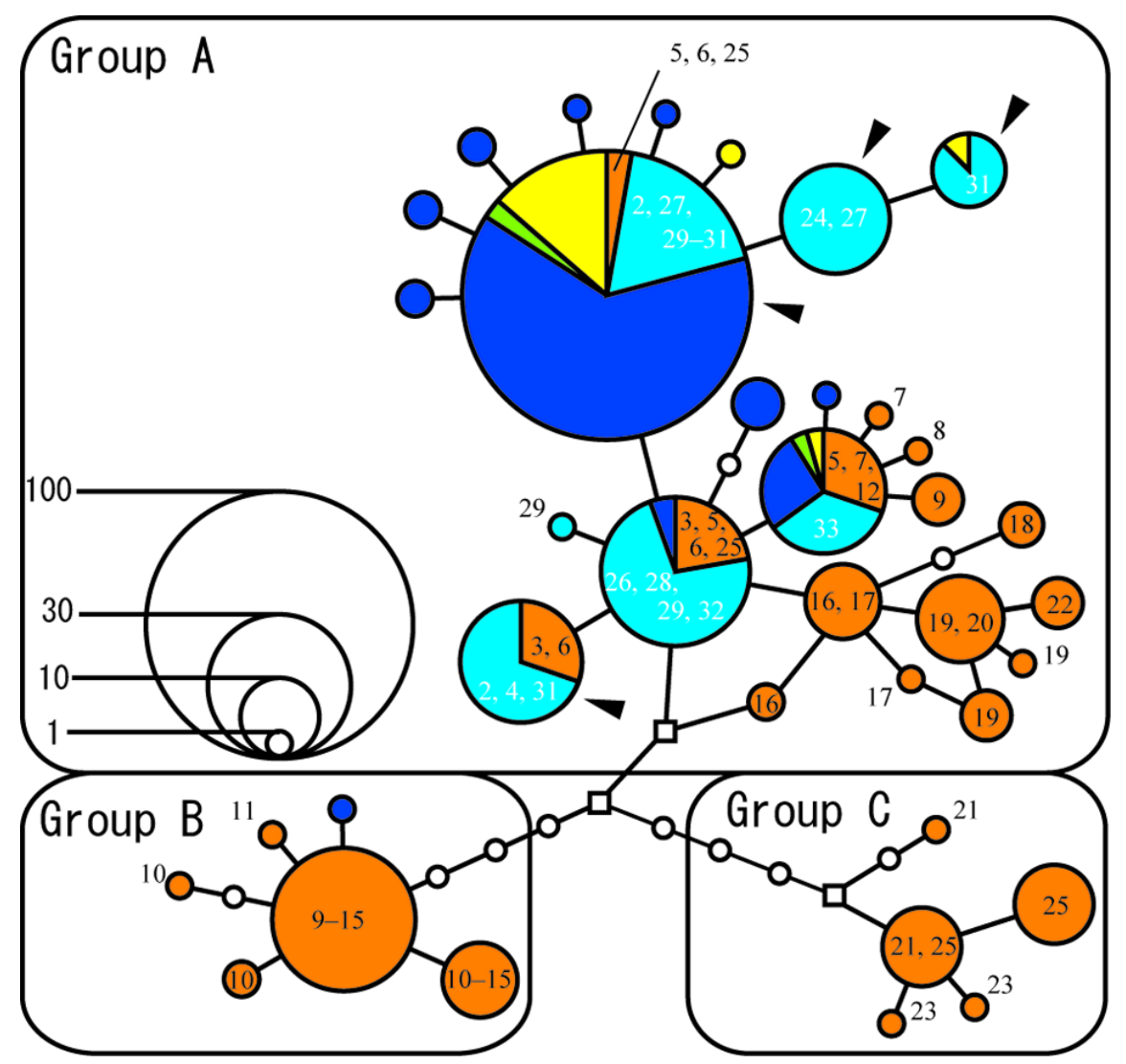

$\square$ Japan, sexual $\square$ Japan, parthenogenetic $\square$ Europe

$\square$ North America $\square$ Argentina 


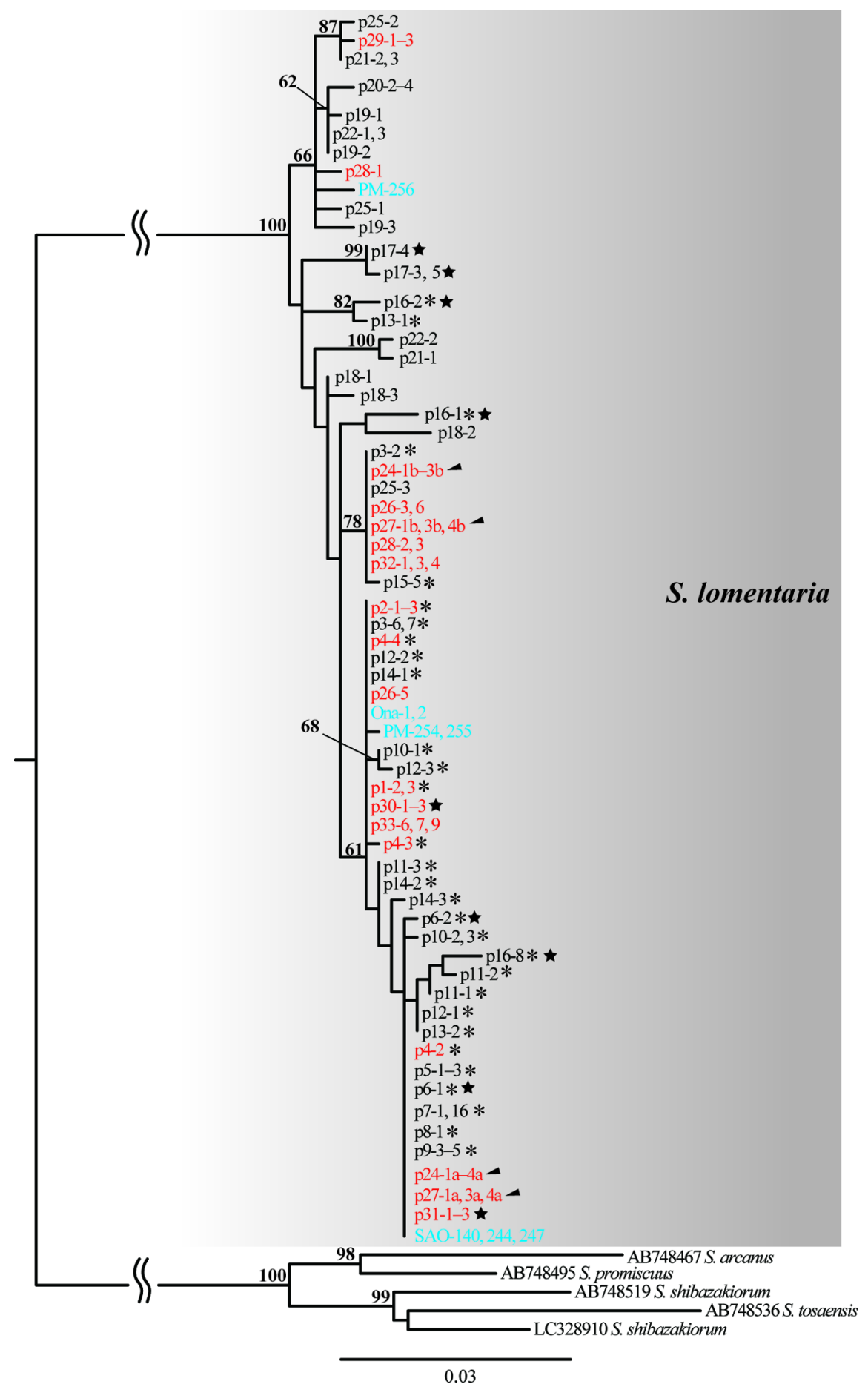




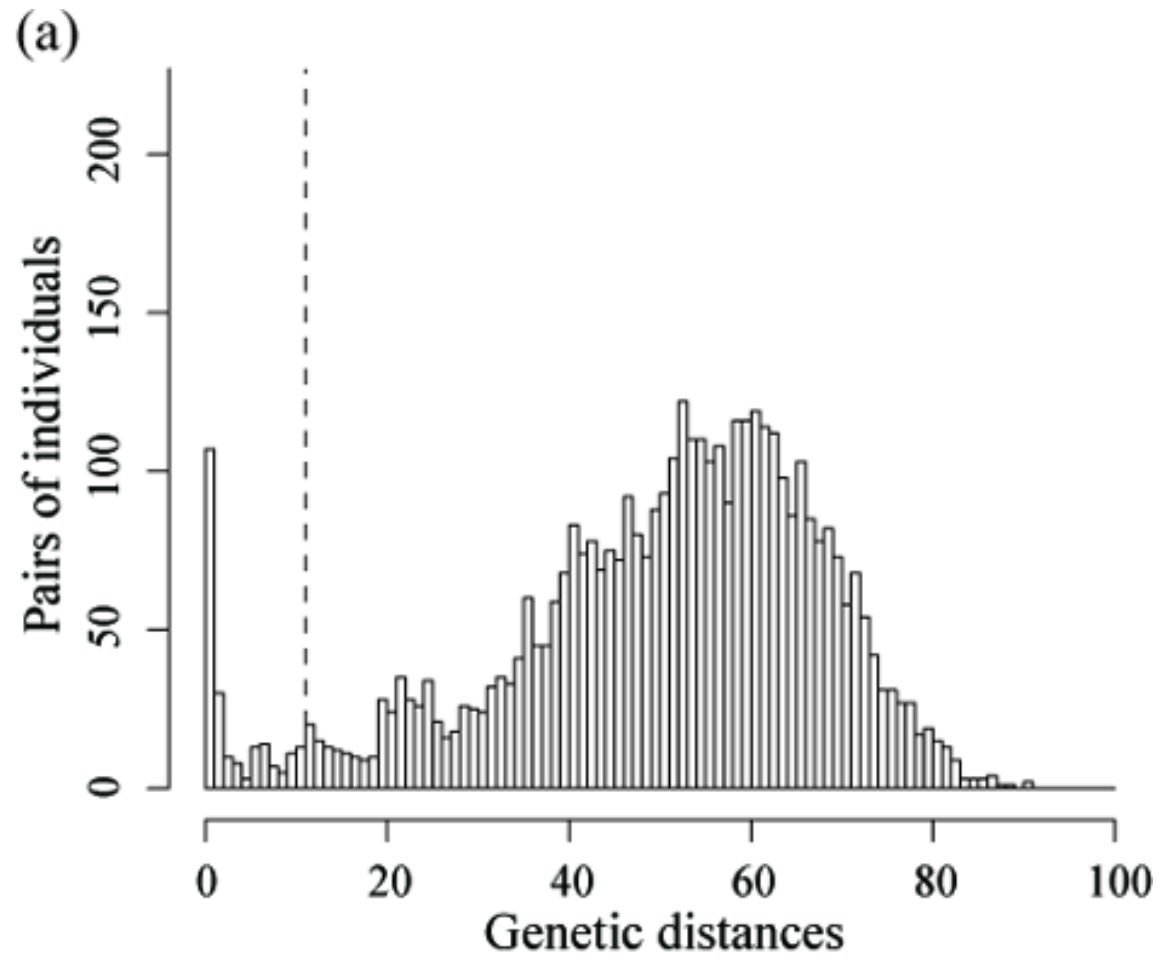

(b)

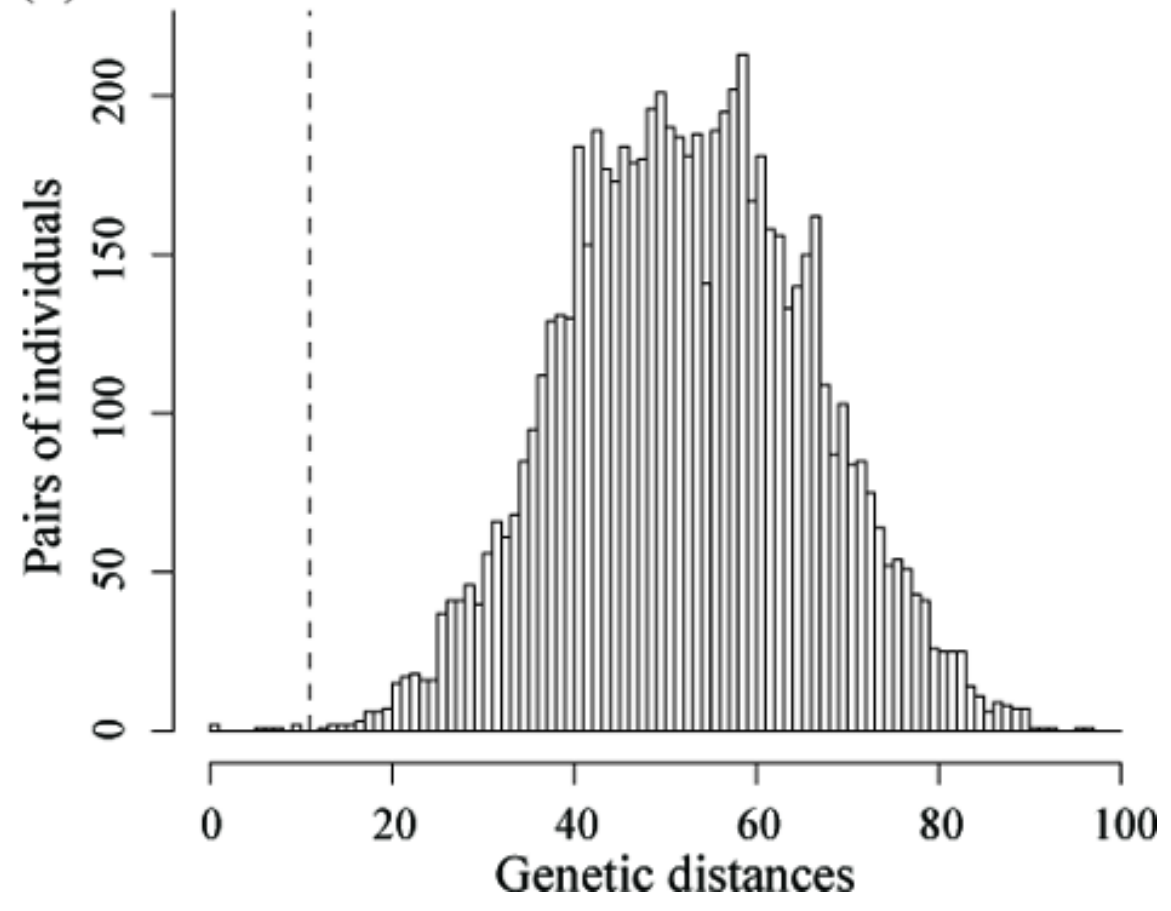



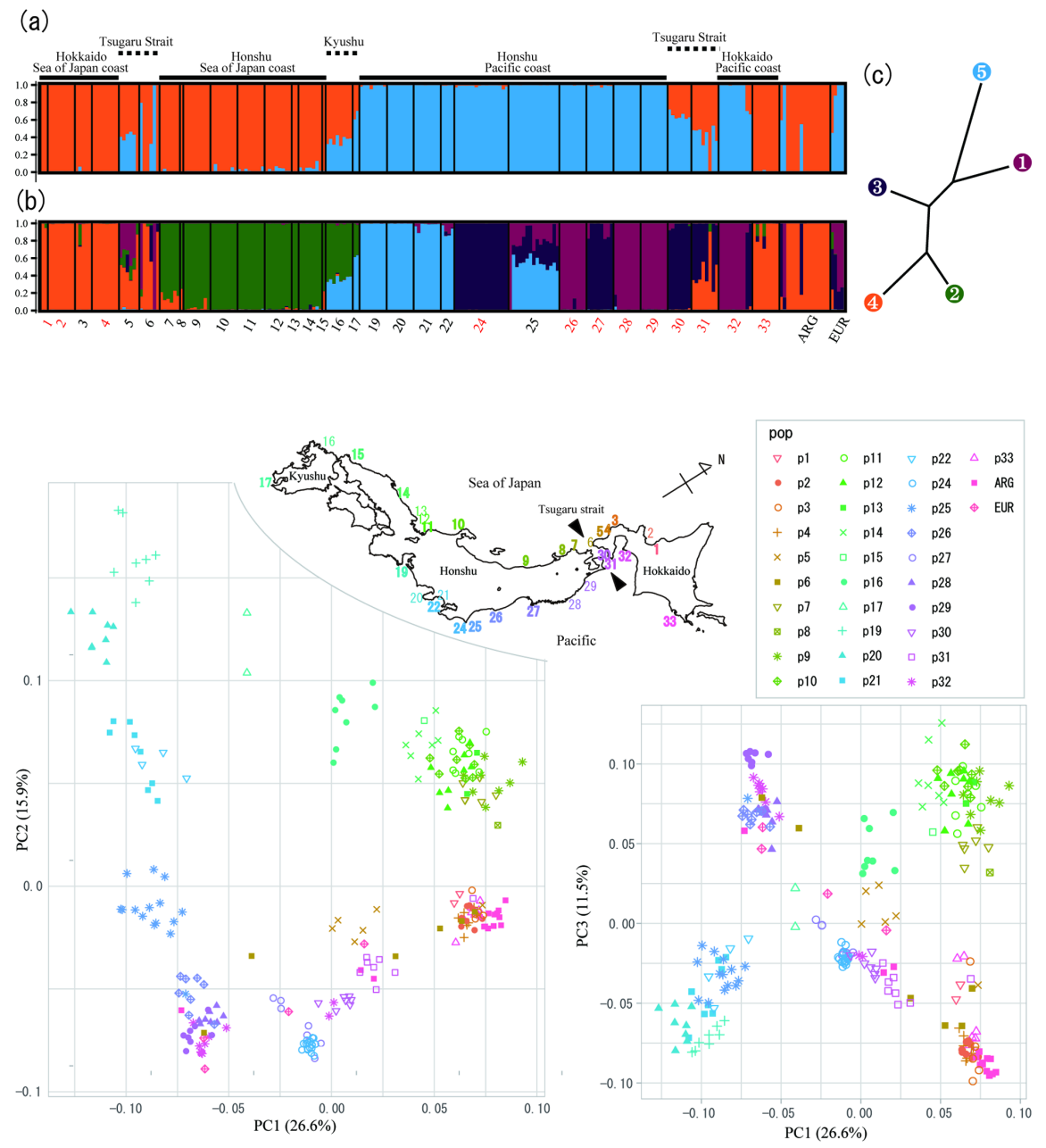

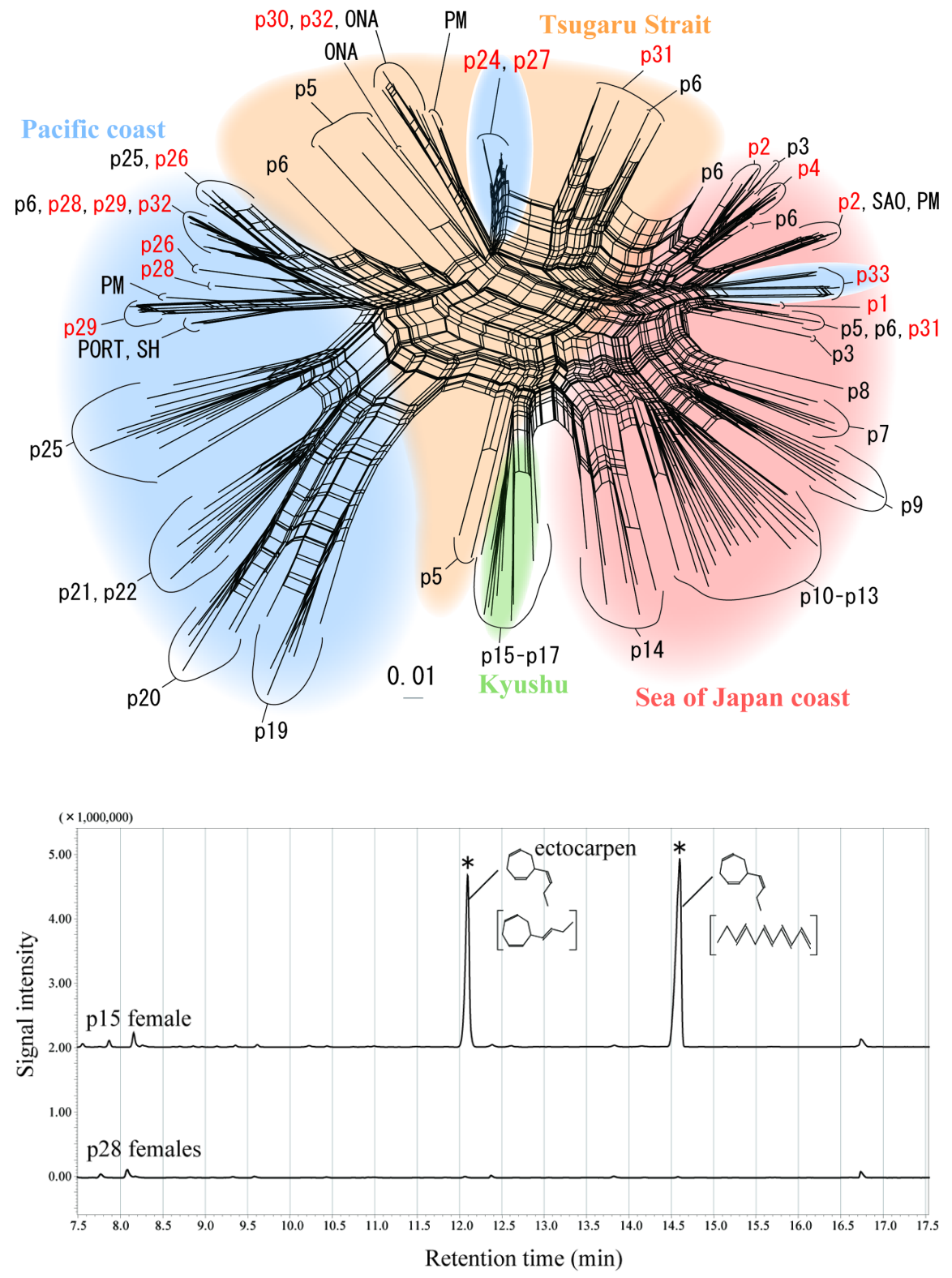